\title{
A Tecnologia da Informação (TI) a serviço da gestão pública: vantagens da utilização da Videoconferência em audiências penais
}

\section{Information Technology (IT) in the service of public administration: advantages of using Videoconferencing in criminal hearings}

\author{
Rodrigo Zanetti Negrini Especialista em Gestão Pública. Universidade Federal de Santa Maria \\ (UFSM) - Brasil. rznegrini@gmail.com \\ Daniel Luís Arenhardt Doutor em Administração. Universidade Federal de Santa Maria \\ (UFSM) - Brasil. daniel.arenhardt@ufsm.br. \\ Eugênio de Oliveira Simonetto Doutor em Administração. Universidade Federal de Santa Maria \\ (UFSM) - Brasil. eosimonetto@gmail.com
}

Cristiano Lanza Savegnago Mestre em Políticas Públicas e Gestão Educacional. Universidade Federal de Santa Maria (UFSM) - Brasil. cristianolanza@hotmail.com

\section{RESUMO}

Esse artigo trata sobre a utilização de equipamentos de Vídeo Audiência, Teleconferência ou Videoconferência no processo penal brasileiro. Busca discutir sua legalidade e identificar vantagens de sua aplicação em detrimento ao modelo convencional de audiências penais. Para isso, realizou-se uma revisão bibliográfica, onde foi possível constatar sua viabilidade jurídica, constitucional e financeira. Tendo em vista que sua utilização atende aos princípios constitucionais da ampla defesa e do contraditório, torna-se inegável os benefícios do seu emprego para o ordenamento jurídico, para a redução de custos da máquina pública e para o aumento dos padrões de segurança dos servidores do judiciário e da segurança pública. As vantagens identificadas na literatura vão ao encontro dessa constatação (segurança dos envolvidos, celeridade e economicidade), demonstrando os ganhos advindos de sua aplicação. Inversamente à crítica existente, a realização de audiências por videoconferência preserva os direitos e garantias individuais declaradas pela Constituição da República Federativa do Brasil aos apenados ou réus - uma vez que lhes é garantido o direito de realizar entrevista reservada e antecipada com seu Defensor, assegurando, assim, o sigilo entre advogado e seu cliente.

Palavras-chave: Teleconferência. Gestão Pública. Poder judiciário.

\begin{abstract}
This paper discusses the use of Video Hearing, Teleconference, or Videoconference equipment in the Brazilian criminal proceedings. It discusses its legality and identifies advantages of its application over the conventional model of criminal hearings. For this purpose, a bibliographic review was performed, where it was possible to verify its legal, constitutional and financial viability. Considering that its use complies with the constitutional principles of legal defense and contradictory, the benefits of its use for the legal system become undeniable, as it allows for the reduction of costs of the public entity and for the increase of the security standards of the judiciary's servers and for the public security. The advantages identified in the literature are in agreement with this finding (safety of those involved, speed and economy), demonstrating the gains from its application. Contrary to existing criticism, holding videoconference hearings preserves the individual rights and the guarantees declared by the Constitution of the Federative Republic of Brazil to convicts or defendants - since they are guaranteed the right to conduct an early and reserved interview with their advocate, thus ensuring confidentiality between lawyer and client.
\end{abstract}

Keywords: Teleconference. Public Management. Judicial branch. 


\section{INTRODUÇÃO}

Diante do ritmo acelerado com que ocorrem as mudanças no século XXI, a Teleconferência tem se apresentado como uma solução frente à alta demanda processual a que o sistema judiciário tem sido submetido nos últimos tempos. Sob o ponto de vista da gestão, vê-se uma oportunidade de reduzir custos e aumentar a produtividade ao mesmo tempo em que se aumenta os padrões de segurança (BARROS, 2010; BARROS; ROMÃO, 2006; GOMES, 2007). Sua utilização também assegura que todos os prazos sejam cumpridos - evitando complicações processuais geradas por eventuais atrasos, ao mesmo tempo em que preserva os princípios legais instituídos pela Constituição da República Federativa do Brasil, conforme artigo 5 (BRASIL, 1988).

A Videoconferência, também conhecida como Teleconferência, é uma sessão de comunicação em vídeo realizada entre duas ou mais pessoas que se encontram geograficamente separadas" (BARROS, 2010), e sua operacionalização depende de acesso à internet. Ela promove o encontro entre duas ou mais pessoas que estão em locais diferentes, por meio da utilização da Tecnologia de Informação e Comunicação (TIC). No meio jurídico, sua utilização permite a realização de audiências entre as partes interessadas de um processo criminal, como juiz, Ministério Público, defensores públicos ou advogados de defesa, réu ou acusado e vítima proporcionando o desfecho de um processo criminal que pode resultar na absolvição, condenação ou apelação de uma sentença.

Jurisdições em todo o mundo estão adotando videoconferência e a tecnologia está se tornando uma interface importante para as interações dos presos com tribunais e consultores jurídicos (McKAY, 2016). No Brasil, a primeira experiência com "teleaudiência" em ambiente jurídico ocorreu na cidade de Campinas/SP, em agosto de 1996 (GOMES, 2007). No entanto, mesmo diante da disseminação das TICs e demais avanços tecnológicos vivenciados pela sociedade atual, parte considerável dos operadores de direito têm se mostrado resistente ao uso das Teleconferências em audiências criminais (BARROS, 2010).

Dessa forma, a Gestão Pública vislumbra, através da videoconferência, um avanço no ordenamento jurídico do país, contribuindo para a desoneração do Estado e do contribuinte (BARROS, 2010). Sua aplicação permite a oferta de serviços transparentes, rápidos e seguros à sociedade, facilitados pelo acesso às novas tecnologias, sem deixar que os direitos à ampla defesa e ao contraditório (previsto às pessoas privadas de liberdade), sejam desrespeitados. Essa modalidade de audiência também garante todos os demais direitos previstos na Constituição da República Federativa do Brasil, em especial no seu artigo $5^{\circ}$.

Diante disso, o objetivo desse estudo é discutir a legalidade da utilização da Teleconferência em audiências penais. Adicionalmente, esta pesquisa busca descrever as vantagens do uso da Teleconferência para a gestão pública. Para tal, uma revisão bibliográfica foi realizada, identificando e analisando documentos que discorrem sobre a utilização dessa ferramenta no sistema judiciário brasileiro. Com isso, o estudo possibilitou defrontar pontos de vista distintos, amparados em artigos científicos, leis em vigor e tratados internacionais.

Nesse cenário, percebe-se o governo eletrônico (e-GOV) e as Tecnologias de Informação e Comunicação (TICS) sendo utilizados de governo para governo (mais especificamente, do poder executivo para o poder judiciário) através da realização das Teleconferências nas varas de execuções criminais (VECs). Ou seja, um novo e abrangente assunto traçando um caminho evolutivo na execução processual com inúmeras vantagens, como redução de custos, modernidade ao sistema, rapidez (FIOREZE, 2005, que podem tornar a gestão pública mais eficiente e menos dispendiosa. A utilização de Teleconferências em procedimentos penais no país se traduz em uma gestão pública mais moderna (SOARES; MACHADO, 2007) e com menor burocracia (GOMES, 2009) - o que diminui custos, tempo de tramitação de processos e trâmites jurídicos (GUIMARÃES, 2008). Também permite uma guarda e custódia de apenados com maior segurança, facilitando a comunicação entre gestões separadas por quilômetros de distância por meio da utilização de um sistema on-line em tempo real (que tem por objetivo a otimização dos processos e a melhoria do serviço prestado) (BARROS, 2010).

Nesse sentido, esse estudo se justifica porque poucos trabalhos são encontrados sobre a relevância da utilização da videoconferência na esfera jurídica. Especificamente no âmbito criminal, sua importância é 
ainda maior, haja vista tratar-se de ambiente onde fatores como recursos financeiros alocados e segurança dos envolvidos são acentuados. Assim, esse estudo visa contribuir nesse caminho.

O presente artigo está divido da seguinte forma: após a presente introdução, será realizada uma revisão da literatura tratando sobre os temas pertinentes a temática "Teleconferência". Em seguida, serão descritos os procedimentos metodológicos adotados para a realização da pesquisa. $\mathrm{O}$ tópico seguinte apresentará os resultados. Por fim, tem-se as conclusões do estudo.

\section{REVISÃO DA LITERATURA}

A revisão da literatura está dividida em quatro itens, conforme segue: o primeiro tópico discorrerá sobre o sistema de Teleconferência propriamente dito; o segundo item abordará a importância da Tecnologia da Informação para o uso da Teleconferência; o terceiro item descreverá a audiência de custódia e o quarto tópico a audiência de conciliação (ambas passíveis de utilização da ferramenta objeto desse estudo).

\subsection{Sistema de Teleconferência}

A Teleconferência é uma sessão de comunicação em vídeo e áudio realizada entre pessoas que se encontram em mais de um local. Conforme descreve Gomes (2007), a fabricação de provas através de meios eletrônicos tem se mostrado controversa e gerado polêmicas por parte de atuadores do ramo do direito, apesar dos inúmeros benefícios proporcionados pelo seu uso. Dessa forma, a Teleconferência tem sido causa de inúmeros debates. Contudo, em decorrência do crescimento exponencial das demandas processuais (GOMES; FREITAS, 2017), percebesse que seu uso é um caminho sem volta.

A primeira videoconferência que se tem registro foi realizada em 27 de agosto de 1996, na cidade de Campinas/SP. Também em 1996, na cidade de São Paulo/SP, realizou-se, pelo juiz de Direito Luiz Flávio Gomes, uma audiência ocorrida por mensagens de texto enviadas por e-mail (através de perguntas e respostas de forma digitadas) - o que difere da proposta atual, mas sendo considerado, à época, um ato precursor (FIOREZE, 2005).

Conforme é descrito por Fioreze (2005), integram o sistema que interliga uma sala de audiência de um Fórum de Comarca com a sala de audiência de um presídio (1) câmeras de vídeo e (2) sistema de imagem e som. Tais equipamentos permitem que o juiz, defensores, advogados, Ministério Público, agentes penitenciários e o próprio preso possam ver e ouvir uns aos outros em tempo real. Na sala de audiência do presídio localizam-se, geralmente, o preso, dois agentes, dois monitores de vídeo de 29 polegadas, uma impressora, uma câmera conectada ao computador e um microfone. Da mesma forma, na sala de audiência do Fórum (onde encontra-se o juiz), ficam a sua disposição os mesmos equipamentos. Tudo é conectado à Internet e sua transmissão ocorre em tempo real (para que o juiz conduza a audiência e para que o Ministério Público, defensores e advogados possam participar).

O sistema é operacionalizado por meio de software de computador, telões, duas câmeras $360^{\circ}$ e um canal que interliga os dois pontos de maneira exclusiva e segura. Por meio de um controle remoto, o magistrado comanda o sistema e direciona a câmera de forma a enquadrar qualquer pessoa que esteja na sala onde o réu se encontra (dentro da própria penitenciária). De outro lado encontra-se o detento, que possui perfeita visão do magistrado. Tomado o depoimento, o réu é enviado à impressora da sala para que leia e assine o que foi declarado. Em seguida, o depoimento é enviado ao Fórum, tornando o procedimento rápido, simples e econômico (FIOREZE, 2005). Dessa forma, o uso de câmeras, telas de televisão, microfones e altofalantes vinculados à Internet ou conexões telefônicas permite que os juízes se comuniquem com as partes através de telas audiovisuais e presidam audiências remotamente (ROWDEN; WALLCE, 2018). Na Figura 1 temse um desenho representando a sala de audiência do Fórum, onde o juiz coordena a sessão. 
Figura 1 - Esboço de câmeras na sala de audiência, captando a imagem do juiz no banco

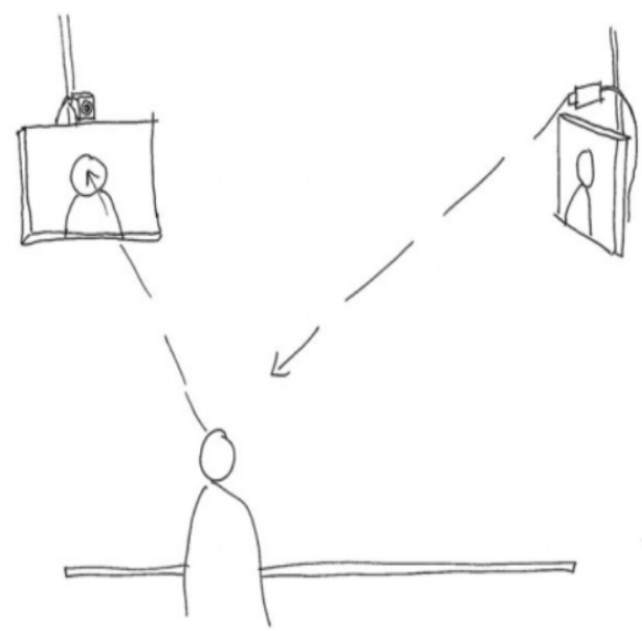

Fonte: Rowden; Wallace (2018, p. 517).

O sistema de Vídeo Audiências ou Teleconferências brasileiro foi criado pelo Conselho Nacional de Justiça (CNJ) para ser uma ferramenta facilitadora do trabalho dos magistrados e também dos servidores (tanto do judiciário como do executivo), de forma a registrar audiências e também emitir atas de forma automática. O cadastro dos usuários que serão operadores desse sistema é realizado pelo departamento de monitoramento e fiscalização do sistema carcerário do Conselho Nacional de Justiça (CNJ), sendo que se faz necessária uma indicação dos profissionais que terão acesso ao sistema (realizado pelos juízes responsáveis). Assim que o cadastro for confirmado, o servidor receberá um e-mail de confirmação com uma senha provisória. A partir de então, o usuário poderá entrar no sistema de controle de acesso do CNJ (www.cnj.jus.br/corporativo//) e, utilizando seu Cadastro de Pessoa Física (CPF), alterar sua senha de acesso (por questões de segurança). (BRASIL, 2019).

Um dos procedimentos mais comuns de utilização de Teleconferência refere-se à audiência de custódia. Trata-se de um instrumento processual que determina que todo preso em flagrante deve ser conduzido à presença da autoridade judicial no prazo máximo de até 24 horas (BRASIL, 2015). Isso faz-se necessário para que se avalie a legalidade e a necessidade de manutenção da prisão (CORDEIRO; COUTINHO, 2018), ao mesmo tempo em que são analisados quesitos referentes à prisão e a conduta dos agentes envolvidos. O tópico a seguir abordará a importância da Tecnologia da Informação na utilização de Teleconferências no âmbito jurídico.

\subsection{A Tecnologia da Informação (TI) na operacionalização de Teleconferências}

A Tecnologia da informação (TI) é a tecnologia de adquirir, armazenar, estruturar e gerenciar a informação; comprimir e transmitir a informação e, finalmente, processar, acessar e interpretar esta informação (RAY; ACHARYA, 2004). Para Reynolds (2016), a tecnologia da informação inclui todas as ferramentas que capturam, armazenam, processam, trocam e usam informações. O campo de Tl inclui hardware de computador (como computadores mainframe, servidores, desktops, laptops, tablets e smartphones, software), sistemas operacionais e aplicativos para executar várias funções, bem como redes e equipamentos relacionados, como modems, roteadores e switches, e bancos de dados para armazenamento de dados importantes.

Especificamente em relação a videoconferências, o Conselho Nacional de Justiça (BRASIL, 2019), em seu endereço eletrônico, descreve alguns requisitos mínimos para utilização do sistema tais como: computador ou notebook com acesso à internet, Webcam, Microfone, Navegador Chrome - versão 31 ou superior, ou Navegador Firefox - versão 38 ou superior. Já como requisitos mínimos de rede nos Tribunais, para que o Sistema Nacional de Videoconferência funcione, é necessário que as configurações específicas sejam realizadas pelo pessoal de segurança de rede em cada localidade que for utilizar o sistema. Caso as 
configurações não sejam realizadas em um determinado Tribunal, somente serão possíveis comunicações internas. Qualquer pessoa que não esteja na rede interna do Tribunal, apesar de conseguir entrar na sala virtual de conferência, não será vista ou escutada (BRASIL, 2018a). Com esses equipamentos, conforme descreve Barros (2010), é possível acompanhar as imagens do que está acontecendo, em tempo real, tanto na sala do fórum quanto da unidade prisional. Enfim, a tecnologia modifica a gestão dos tribunais e o acesso à justiça, com benefícios, entre outros, em termos de celeridade processual (FERREIRA, 2015). O próximo tópico discute conceitos relacionados à audiência de custódia e audiência de conciliação.

\subsection{Audiência de custódia e audiência de conciliação}

A audiência de custódia refere-se a um mecanismo de verificação da necessidade cautelar, com previsão no art. 70, item 5, do Pacto de São José da Costa Rica ou a Convenção Americana sobre Direitos Humanos e pelo Art. 9o, item 3 do Pacto Internacional sobre Direitos Civis e Políticos de Nova lorque (promulgado no Brasil pelo Decreto n. 592, de 6 de julho de 1992), o qual estabelece:

Qualquer pessoa presa ou encarcerada em virtude de infração penal deverá ser conduzida, sem demora, à presença do juiz ou de outra autoridade habilitada por lei a exercer funções judiciais e terá o direito de ser julgada em prazo razoável ou de ser posta em liberdade. A prisão preventiva de pessoas que aguardam julgamento não deverá constituir a regra geral, mas a soltura poderá estar condicionada a garantias que assegurem o comparecimento da pessoa em questão à audiência, a todos os atos do processo e, se necessário for, para a execução da sentença (ART. 9, ITEM 3, BRASIL, 1992).

A esse respeito, conforme estabelece o Código de Processo Penal brasileiro (Lei 3.689/1941), quatro elementos são determinantes para prisão em flagrante: detenção, locomoção do preso à autoridade policial, lavratura do auto de prisão em flagrante e o encarceramento. Dentro do prazo de 24 horas da prisão em flagrante, o segregado deve ser conduzido a autoridade de um juiz, para a verificação dos elementos a que levaram sua prisão (BRASIL, 2015), assim como, se houve a presença de um Advogado no ato da prisão e demais elementos de materialidade e a necessidade cautelar. Somente assim, o juiz pode determinar sua prisão preventiva ou temporária, ou também seu relaxamento mediante medidas cautelares diversas da prisão. Tendo em vista que o controle sobre a prisão é estritamente do Poder Judiciário, se faz necessária a condução do segregado à presença de um magistrado para sua eventual homologação (BRASIL, 1941). Na opinião de Ribeiro e Novaes (2018), a realização de audiência de custódia por meio de videoconferência tem dividido a opinião de especialistas; enquanto alguns entendem ser perfeitamente possível, outros criticam sua utilização. A esse respeito, entre as críticas identificadas, encontram-se a falta de contato físico entre réu e juiz (GOMES, 2008), a hostilidade do presídio - o que pode inibir as declarações/acusações do réu (TAVARES, 2011) a dificuldade do juiz em extrair impressões pessoais do acusado para aplicação da pena (TAVARES, 2011) e o cerceamento do caráter antropológico e humanista da audiência de custódia (CAMARGO, 2015; SANTOS, 2016). Os favoráveis à utilização da videoconferência argumentam, por sua vez, celeridade processual (GOMES, 2008), irrestrita legitimidade de sua utilização (BARROS, 2010), garantia dos direitos fundamentais do preso (SOUZA; NUNES, 2018) e racionalização dos recursos públicos (McKAY, 2016).

Por seu turno, nas infrações de menor potencial ofensivo (IMPO), a audiência de conciliação se faz um instrumento viabilizador de acordos entre as partes. Estabelecida na Lei 9.099/1995 e ampliada pela Lei $10.259 / 2001$, ela trouxe consigo consideráveis mudanças no campo do direito penal, instituindo os juizados especiais cíveis e criminais no âmbito da justiça Federal e solucionando conflitos acerca da lesão ao princípio da igualdade. A Lei 9.099/1995, em seu artigo 61, considera como infração penal de menor potencial ofensivo as contravenções penais e os crimes a que a lei comine pena máxima não superior a 2 (dois) anos, e aqueles apenados alternativamente com multa (BRASIL, 1995).

A audiência de conciliação é uma forma de solução de conflitos que está disponível nos tribunais diariamente. Assim, é marcada uma conversa entre as partes, que será mediada por uma pessoa imparcial - 
chamada conciliador, que favorece o diálogo e faz sugestões para a celebração de acordos, evitando o desgaste do processo judicial (BRASIL, 2010b; SALES; CHAVES, 2014). É necessária a aceitação do acordo por todas as partes. Caso todos aceitem, será homologado por um juiz e seguirá para a fase de execução. Caso contrário, o processo toma seu curso normal (BRASIL, 2010b). As matérias que cabem a audiência de conciliação estão disponíveis no site do http://cnj.jus.br/conciliacao. A seguir, discorre-se sobre a metodologia adotada na presente pesquisa.

\section{METODOLOGIA}

Projetar pesquisas que identifiquem as maneiras pelas quais as pessoas em uma determinada situação veem seus mundos é um ponto de partida sensato para pesquisas significativas (BEAN, 2011). De acordo com Crotty (1998), a metodologia se refere à estratégia, ao plano de ação, ao processo ou o projeto que estão por detrás da escolha e utilização de métodos específicos. É ela quem liga a escolha e o uso de métodos aos resultados desejados. Nesse sentido e considerando o objetivo do estudo, a metodologia adotada nesse trabalho foi a revisão bibliográfica.

A pesquisa bibliográfica pode ser definida como "a revisão da literatura sobre as principais teorias que norteiam o trabalho científico" (PIZZANI, et al., 2012). Sua principal característica é o fato de que o campo onde se fará a coleta dos dados é a própria bibliografia sobre o tema escolhido para investigação (TOZONI-REIS, 2009). De acordo com Soares, Picolli e Casagrande (2018), na área da Administração e Contabilidade é comum que pesquisadores de contabilidade tributária, comércio internacional e administração pública realizem pesquisas de natureza bibliográfica.

Conforme descrevem Lima e Mioto (2007), a pesquisa bibliográfica não é apenas uma revisão de literatura, mas implica em um conjunto ordenado de procedimentos de busca por soluções estreitamente ligados ao objeto de estudo. Nesse sentido, tendo em vista o objetivo do trabalho, a revisão bibliográfica foi dividida em duas etapas.

A primeira etapa consistiu em buscar legislações, tratados, leis e documentos que versassem sobre a utilização da Teleconferência em audiências penais. O intuito foi constatar (amparado em registros oficiais) a legalidade do uso da ferramenta pelo judiciário. Os seguintes documentos foram identificados e analisados:

- Código de Processo Penal (Decreto-Lei n. 3.689, de 03 de outubro de 1941);

- Código de Processo Civil (Lei n. 13.105, de 16 de março de 2015);

- Constituição da República Federativa do Brasil;

- Site do Conselho Nacional de Justiça (CNJ);

- Sistema de Videoconferência, do CNJ;

- Pacto Internacional de Direitos Civis (Decreto n. 592, de 06 de julho de 1992);

- Convenção Americana dos Direitos Humanos (Decreto n. 678, de 06 de novembro de 1992);

- Convenção das Nações Unidas contra o Crime Organizado Transnacional (Decreto n. 5.015, de 12 de março de 2004);

- Tratado de Cooperação Jurídica em Matéria Penal (Decreto n. 6.974, de 07 de outubro de 2009);

- Lei n. 11.419, de 19 de dezembro de 2006;

- Resolução n. 105, de 06/04/2010, do CNJ.

Após uma cuidadosa leitura dos documentos, foi possível identificar vários excertos, citações e tópicos relacionados à utilização de Teleconferência em audiências penais. Pontos de vista distintos também foram encontrados e trazidos para o debate nos resultados que foram apresentados.

A segunda etapa consistiu em identificar trabalhos acadêmicos que tratassem sobre a temática em questão e que apresentassem, claramente, vantagens de se utilizar a Teleconferência no ambiente penal. Para isso, adotou-se os quatro passos sugeridos por Andrade (2010) como forma de conferir clareza aos procedimentos metodológicos aplicados.

Primeiro passo: acervo inicial. A primeira etapa refere-se ao levantamento de referências sobre o tema. A esse respeito, foi realizado uma busca por trabalhos na plataforma Google Acadêmico (https://scholar.google.com.br). Como palavras de busca, foi inserida a sentença "teleconferência audiência 
penal"; e como idioma, o português. A busca resultou no retorno de 362 registros. Considerando o elevado número de trabalhos, foi realizada uma breve leitura dos títulos dos documentos e excluídos aqueles que não tivessem relação com o sistema judiciário, bem como registros classificados como citações, monografias de graduação, dissertações, teses e livros. Após a triagem, 45 documentos foram selecionados.

Segundo passo: leitura prévia ou pré-leitura. A etapa seguinte consistiu em uma leitura prévia para identificação de artigos que realmente mantivessem relação com a pesquisa, relacionando a temática audiência penal/judicial com a utilização de Teleconferência. Foram eliminadas obras ou trabalhos que apenas citavam as palavras-chave selecionadas, mas não aprofundavam o assunto. Nessa etapa, restaram 18 artigos.

Terceiro passo: leitura seletiva. Após a coleta e a leitura superficial para identificação dos trabalhos que de fato poderiam contribuir para a pesquisa, foi realizada uma leitura cuidadosa dos principais artigos selecionados, tendo em vista sua contribuição para a pesquisa. Nesse ponto, 12 artigos foram selecionados, uma vez que apresentaram de forma mais direta e clara vantagens em se utilizar a Teleconferência em audiências penais.

Quarto passo: leitura crítica ou reflexiva. Por fim, os artigos foram agrupados e classificados de acordo com as vantagens identificadas para a gestão pública ao se utilizar a Teleconferência em audiências penais. Os autores Marco Antônio de Barros e Rodrigo Carneiro Gomes tiveram mais de um artigo selecionado - o que pressupõe serem referências sobre o assunto. O Quadro 1 descreve os passos adotados para a identificação dos artigos, esclarecendo os critérios de inclusão e exclusão utilizados.

Quadro 1 - Critérios de inclusão e exclusão dos documentos

\begin{tabular}{|c|c|c|c|}
\hline Passos & Critério(s) de inclusão & Critério(s) de exclusão & Resultado \\
\hline $1^{\circ}$ passo & $\begin{array}{l}\text { Documentos com as palavras: } \\
\text { teleconferência audiência penal; } \\
\text { idioma português }\end{array}$ & $\begin{array}{l}\text { Documentos sem relação com o } \\
\text { sistema judiciário e enquadrados } \\
\text { como citações, monografias, } \\
\text { dissertações, teses e livros }\end{array}$ & 45 documentos \\
\hline $2^{\circ}$ passo & $\begin{array}{l}\text { Documentos que discutem as } \\
\text { temáticas e a relação entre: } \\
\text { audiência } \\
\text { teleconferência } \\
\text { videoconal/judicial, } \\
\text { e/ou }\end{array}$ & $\begin{array}{l}\text { Documentos sem relação direta } \\
\text { com a temática do trabalho e } \\
\text { com citações superficiais das } \\
\text { palavras objeto do estudo }\end{array}$ & 18 documentos \\
\hline $3^{\circ}$ passo & $\begin{array}{l}\text { Identificação/citação } \quad \text { de } \\
\text { vantagens em se utilizar a } \\
\text { teleconferência }\end{array}$ & $\begin{array}{l}\text { Artigos sem clara apresentação } \\
\text { de vantagens na utilização de } \\
\text { teleconferência }\end{array}$ & 12 documentos \\
\hline $4^{\circ}$ passo & $\begin{array}{l}\text { Agrupamento/classificação das } \\
\text { vantagens identificadas }\end{array}$ & Não há & 12 documentos \\
\hline
\end{tabular}

Fonte: elaborado pelos autores (2019).

Ao final, juntamente com o aprofundamento das legislações e tratados que descrevem sobre o assunto, foi possível comprovar a licitude da utilização de Teleconferências, bem como identificar três principais vantagens de sua adoção (se comparado ao modelo tradicional de audiências no âmbito do poder judiciário). A seguir, apresenta-se os resultados do estudo.

\section{RESULTADOS}

Os resultados do presente estudo serão apresentados em duas etapas. Conforme descrito na introdução do trabalho, o objetivo do presente artigo é discutir a legalidade da utilização da Teleconferência em audiências penais, bem como descrever as vantagens de sua utilização para a gestão pública. Dessa forma, o primeiro capítulo busca discutir a legalidade da ferramenta; e o segundo tópico, por seu turno, apresenta as vantagens identificadas na literatura. 


\subsection{Discussão sobre a legalidade do uso da Teleconferência em audiências penais}

Quanto aos aspectos legais envolvidos na utilização de Teleconferências, o aprofundamento do tema permitiu a constatação da inexistência de vedação legal. A esse respeito, verifica-se que o próprio Código de Processo Penal (CPP) admite a realização de qualquer meio de prova desde que não seja proibido por lei, trazendo, dessa forma, licitude à Teleconferência (que vem a preservar a ampla defesa e o contraditório, bem como respeita todos os direitos individuais previstos na Constituição). O próprio Conselho Nacional de Justiça, por intermédio da Resolução n. 105/2010, formulou regras a respeito da documentação nos depoimentos por meio do sistema audiovisual e realização de interrogatório e inquirição de testemunhas por Teleconferência. Anteriormente, o Código de Processo Penal já apresentava regras a respeito do tema, notadamente em seus artigos 185, 217 e 222 (BRASIL, 2019).

Em relação à presença de advogado, ao preso interrogado é garantida a assistência efetiva durante toda a realização do ato, preferencialmente com a participação de, pelo menos, dois advogados (BARROS, 2010). A esse respeito, Barros (2010) também declara que o ideal seria um advogado lhe acompanhando nas dependências do presídio e outro na própria sala de audiências.

De outra banda, verifica-se posicionamentos contrários ao sistema de Teleconferências, tendo em vista que nessa modalidade não há contato físico entre réu e juiz. Por esse motivo, muitas autoridades e profissionais do ramo do direito apresentam resistência à implantação desse modelo de audiências, baseandose no Pacto Internacional de Direitos Civis e Políticos e na Convenção Americana dos Direitos Humanos (mais conhecido como Pacto de São José da Costa Rica). Conforme essa Convenção, é um direito do réu preso ser conduzido pessoalmente à presença do juiz, conforme é descrito no Art 70, item 5 .

Toda pessoa presa, detida ou retida deve ser conduzida, sem demora, à presença de um juiz ou outra autoridade autorizada por lei a exercer funções judiciais e tem o direito de ser julgada em prazo razoável ou de ser posta em liberdade, sem prejuízo de que prossiga o processo. Sua liberdade pode ser condicionada a garantias que assegurem o seu comparecimento em juízo (COMISSÃO INTERAMERICANA DE DIREITOS HUMANOS, ART. 70, item 5, 1969).

Esse mesmo ponto de vista é defendido por D'Urso (2002), que destaca:

Vozes de todos os cantos do país levantam-se contra essa experiência, pois sob o manto da modernidade e da economia, revela-se perversa e desumana, afastando o acusado da única oportunidade que tem ele de falar ao seu julgador, trazendo frieza e impessoalidade a um interrogatório que poderia, caso aceito, ser realizado por telégrafo, nada diferenciando-se deste (D'URSO, 2002, s/n).

E ainda, no mesmo artigo, o autor defende:

A ausência da voz, do corpo e do 'olho no olho', redunda em prejuízo irreparável para a defesa e para a própria Justiça, que terá de confiar no Diretor do presídio ou n'outro funcionário, que fará a ponte tecnológica com o julgador (D'URSO, 2002, $s / n)$.

Na opinião de McKay (2016), embora essa nova tecnologia prisional ofereça a possibilidade de permeabilidade com o mundo exterior, ela paradoxalmente ocasiona, no entanto, uma maior desconexão da humanidade. $O$ que preocupa é o colapso espacial entre o espaço não judicial da prisão e os espaços da sala de audiências e da consulta jurídica. A autora ainda destaca que a sala de Teleconferência não é uma réplica do espaço da corte, o que compromete a imparcialidade do processo legal e a confidencialidade advogadocliente. 
Em contraponto, há previsão para a utilização de Teleconferências em diversos tratados internacionais. Entre eles, destaca-se o "Tratado de Cooperação Jurídica em Matéria Penal entre a República Federativa do Brasil e a Confederação Suíça" e a "Convenção das Nações Unidas contra o Crime Organizado Transnacional" (conhecida como Tratado de Palermo). Trata-se de convenções posteriores ao Pacto de San José da Costa Rica e, portanto, prevalecem no ordenamento jurídico suas regras, conforme observa-se no trecho a seguir:

Se for possível e em conformidade com os princípios fundamentais do direito interno, quando uma pessoa que se encontre no território de um Estado Parte deva ser ouvida como testemunha ou como perito pelas autoridades judiciais de outro Estado Parte, o primeiro Estado Parte poderá, a pedido do outro, autorizar a sua audição por videoconferência, se não for possível ou desejável que a pessoa compareça no território do Estado Parte requerente. Os Estados Partes poderão acordar em que a audição seja conduzida por uma autoridade judicial do Estado Parte requerente e que a ela assista uma autoridade judicial do Estado Parte requerido (ART. 18, ITEM 18, BRASIL, 2004).

Desta forma, conforme foi apresentado, verifica-se a existência de previsão legal para a utilização de Teleconferências em audiências penais, uma vez que tratados e legislações mais recentes autorizam e incentivam tal operacionalização. Outros tratados, por seu turno, mesmo não declarando sua utilização, em nada obstam o uso do instrumento da teleconferência junto a instrução processual. Além disso, sua utilização segue uma tendência mundial, uma vez que jurisdições em todo o mundo estão adotando tecnologias audiovisuais na justiça criminal e, cada vez mais, prisioneiros aparecem nos tribunais por link de vídeo, permanecendo em espaços de encarceramento (McKAY, 2016).

\subsection{Vantagens identificadas com a utilização de Teleconferência em audiências penais}

As seguintes vantagens foram identificadas na literatura, em relação ao uso da Teleconferência em audiências penais.

\subsubsection{Segurança dos envolvidos}

No que tange aos aspectos relacionados à segurança, pode-se afirmar que se refere a um item de fundamental importância e que possui impacto direto em todos os envolvidos na situação. O uso da Teleconferência em audiências pode coibir fugas, eventuais resgates ou, até mesmo, queima de arquivo (execuções dos apenados por facções rivais) no transporte com escolta policial ou por agentes prisionais durante o deslocamento de saída e retorno ao presídio (GOMES, 2007; GUIMARÃES, 2008; PRADO, 2011). Também minimiza a sensação de insegurança e o possível malefício à sociedade em caso de fuga de apenados.

Além disso, a utilização da Teleconferência em audiências envolvendo encarcerados tende a diminuir a tensão e a carga emocional de policiais, servidores do judiciário e agentes prisionais já extenuados pelas atividades do dia a dia de suas profissões. Consoante Johnson e Wigging (2006), quando o réu ou uma testemunha é um encarcerado, as autoridades governamentais normalmente precisam tomar providências para transportá-lo ao tribunal. Isso pode ser caro e envolver desafios de segurança, dependendo da periculosidade do indivíduo que precisa ser transportado. Além disso, o deslocamento do réu para interrogatórios fora do sistema prisional, exige uma estrutura que garanta a segurança também nas dependências dos Fóruns (GUIMARÃES, 2008).

Ainda em relação ao item "segurança", em alguns casos, onde a escolta é classificada como "de risco", se faz necessário um caro e eficiente aparato de operação policial. Isso ocorre, por exemplo, em casos onde o preso está ameaçado de morte em decorrência de comoção popular, rixas entre facções ou resgate pelo crime organizado. Outra vezes, as escoltas "de risco" são organizadas para garantir a ordem pública em casos de grande repercussão envolvendo famosos ou políticos. Salienta-se que o apenado é custodiado pelo Estado. 
Nesse sentido, a Teleconferência vem auxiliar e preservar também a integridade física do segregado. Considerando que infortúnios causados ao apenado é de responsabilidade do Estado, qualquer ação contra sua integridade é passível de ingresso de ação judicial, o que poderá acarretar indenizações a favor do transgredido e de sua família, onerando os cofres públicos. Essa constatação vai ao encontro do que descreve Bellone (2013). Para o autor, com a utilização da Videoconferência, o transporte de réus não é necessário e o risco para os oficiais que transportam e protegem o apenado durante uma audiência é removido. Os proponentes sustentam que, mantendo o acusado nos limites da prisão, sua dignidade humana pode ser mais bem preservada, uma vez que evitam ao réu entrar no tribunal algemado.

\subsubsection{Celeridade}

Quanto ao aspecto da celeridade processual, a adoção da Teleconferência proporciona consideráveis ganhos, reduzindo o tempo da audiência e fazendo com que um maior número de processos seja despachado pelo Poder Judiciário e seus operadores. Isso permite desafogar o sistema e otimizar o mecanismo processual. Por seu turno, servidores do judiciário logram melhores condições para desenvolver suas atividades do dia-adia - permitindo maior eficiência em suas rotinas.

Para Barros (2010), pode-se afirmar que o a utilização de Videoconferência vai ao encontro do que estabelece a Constituição Federal, em seu art. $5^{\circ}$ - relativo ao princípio constitucional da celeridade processual (julgando o processo criminal com razoável duração, sem causar danos à sociedade e ao acusado). De acordo com Ferreira (2015), a justiça também precisa lidar com os efeitos da globalização, incluindo o uso da tecnologia da informação, que é apresentada como um caminho inegável para levar celeridade aos procedimentos nos tribunais.

A principal justificativa para o uso da tecnologia nos tribunais é obter eficiência. Ao realizar audiências por videoconferência, os tribunais podem remover as restrições de viagem de terceiros, aumentando sua disponibilidade e permitindo que o tribunal agende um evento mais cedo do que quando as partes são obrigadas a comparecer à sala de audiências (YAMAGATA; FOX, 2017). A busca por economia de tempo e dinheiro estimulou o uso da Videoconferência nos tribunais, com a esperança de melhorar a eficiência da administração da justiça (BELLONE, 2013).

Além disso, todos os dados gerados durante as Teleconferências são registrados eletronicamente através de backups. Assim, posteriores consultas podem ser realizadas de forma rápida e segura, tornando todo o conjunto de procedimentos e atividades mais ágil e irrefutável.

\subsubsection{Economicidade}

No tocante à economia para os cofres públicos, o poder judiciário se beneficia pela maior eficiência e rapidez com que o sistema opera. Como exemplo, cita-se o cancelamento de audiências pela ausência de testemunhas. No caso de Videoconferências, é baixa a probabilidade de as partes não comparecerem a um evento programado devido a problemas climáticos ou relacionados a viagens - reduzindo o número de adiamentos de audiências (YAMAGATA; FOX, 2017).

Em julgamentos presenciais, os custos gerados com transporte, segurança e aparato operacional continuam existindo. Em audiências por Teleconferência, por seu turno, uma outra seção é rapidamente iniciada e os desperdícios são minimizados. Tudo é realizado de forma rápida, segura e em tempo real. Dentro desse complexo sistema, o poder judiciário representa o maior valor comprometido (considerando salários, estrutura e servidores envolvidos). Por essa razão, o gestor deve focar na otimização dessa mão de obra. Ou seja, a utilização da Videoconferência proporciona uma economia de recursos financeiros, públicos e privados (FIOREZE, 2005).

Nesse ínterim, aos olhos do gestor público, é possível diminuir a mão de obra do judiciário (considerada a mais onerosa entre os envolvidos), o que minimiza os custos processuais, refletindo em uma economia relevante aos cofres públicos. Existem novos conceitos de tempo e distância em uma sociedade baseada na Internet; é inegável que a celeridade que os cidadãos poderiam esperar do Judiciário aumentou 
em um ambiente em que a pesquisa, a comunicação e as decisões podem ser fornecidas em um clique, economizando tempo e custos (FERREIRA, 2015).

Além disso, há também um ganho econômico para os órgãos da segurança pública, que poupam em combustível, viaturas e policiais - sendo que esses últimos podem permanecer em suas funções de policiamento. Na concepção de Yamagata e Fox (2017), realizar audiências por Videoconferência entre o tribunal e um centro de detenção gera uma economia de custos substancial associada ao transporte. Agentes prisionais, por seu turno, podem priorizar a segurança interna das casas prisionais, revertendo em maior produtividade e retorno dos investimentos nesse setor. O Quadro 2 apresenta as vantagens identificadas na literatura brasileira sobre o assunto, bem como os autores que abordam cada temática.

Quadro 2 - Vantagens das Teleconferências e autores que tratam sobre o tema no Brasil

\begin{tabular}{|c|l|}
\hline Vantagens & \multicolumn{1}{|c|}{ Autores } \\
\hline \multirow{2}{*}{ Segurança } & $\begin{array}{l}\text { Barros, 2010; Barros e Romão, 2006; Fioreze, 2005; Freire, 2013; Gomes, 2007; } \\
\text { Gomes, 2008; Gomes, 2009; Guimarães, 2008; Prado, 2011; Ribeiro e Novaes, } \\
\text { 2018; Tavares, 2011. }\end{array}$ \\
\hline \multirow{2}{*}{ Celeridade } & $\begin{array}{l}\text { Barros, 2010; Barros e Romão, 2006; Fioreze, 2005; Freire, 2013; Gomes, 2007; } \\
\text { Gomes, 2008; Gomes, 2009; Guimarães, 2008; Prado, 2011; Soares e Machado, } \\
\text { 2007; Tavares, 2011. }\end{array}$ \\
\hline \multirow{2}{*}{ Economicidade } & $\begin{array}{l}\text { Barros, 2010; Barros e Romão, 2006; Fioreze, 2005; Freire, 2013; Gomes, 2007; } \\
\text { Gomes, 2008; Gomes, 2009; Guimarães, 2008; Prado, 2011; Prado, 2015; Ribeiro } \\
\text { e Novaes, 2018; Tavares, 2011. }\end{array}$ \\
\hline
\end{tabular}

Fonte: elaborado pelos autores (2019).

Na sequência, apresentam-se as conclusões do estudo.

\section{CONCLUSÃO}

Esse artigo teve como objetivo discutir a legalidade da utilização da Teleconferência em audiências penais, bem como descrever as vantagens de seu uso para a gestão pública. Conforme foi apresentado, não há óbice para sua utilização no ambiente penal, bem como foi possível identificar vantagens importantes relacionadas à diminuição de custos, celeridade dos processos e segurança dos envolvidos e de toda a sociedade como um todo.

Através do olhar do gestor sobre todos os dados relacionados neste artigo, mostrou-se viável a utilização desse método de instrução processual a que o Estado submete as partes. Assim, o uso da Teleconferência contribui para a racionalidade dos recursos públicos. Dados do Conselho Nacional de Justiça, em seu livro "Justiça em Números/2018" (BRASIL, 2018a), apresentam as despesas do Poder Judiciário no anobase de 2017. Conforme o referido documento, os cinco estados classificados como de grande porte (São Paulo, Rio de Janeiro, Minas Gerais, Paraná e Rio Grande do Sul), representam um gasto total de R\$ 26.758.410.714, sendo este valor mais da metade do valor dos demais estados da federação. Ou seja, os cinco maiores tribunais estaduais (TJRS, TJPR, TJSP, TJRJ e TJMG) concentram 65\% do Produto Interno Bruto (PIB) nacional e $51 \%$ da população brasileira, ao passo que os cinco menores tribunais estaduais (TJRR, TJAC, TJAP, TJTO, TJAL) são responsáveis por apenas $2 \%$ do PIB e $3 \%$ da população (BRASIL, 2018a). Essa constatação demonstra a grande contribuição que a adoção de Teleconferências poderia oferecer para a redução dos gastos públicos no que tange ao poder judiciário.

Dessa forma, as conclusões deste estudo nos levam a acreditar que, preservados os direitos e garantias fundamentais, não se encontram óbices à utilização da Videoconferência no âmbito da Justiça, mas, ao contrário, apenas benefícios. Os constantes investimentos por parte do CNJ em tecnologia da informação traduzem um novo rumo para o judiciário, empenhado em superar qualquer resistência que a introdução de um novo método de trabalho possa apresentar. 
O conservadorismo muitas vezes percebido no terreno judiciário é compreensível, haja vista tratar-se de matéria delicada (a privação da liberdade de um indivíduo por parte do Estado, ou da sua colocação em liberdade) - o que pode causar danos irreparáveis ao acusado ou a própria sociedade. Todavia, as Teleconferências começaram a receber jurisprudências e entendimentos por especialistas da área - tornando sua utilização uma possibilidade cada vez mais viável.

A introdução da Tecnologia de Informação (TI) na esfera judicial evita ofícios, requisições, cartas precatórias e cartas rogatórias, proporcionando otimização de mão de obra, material e tempo, eliminando transporte e riscos inerentes aos deslocamentos nas escoltas policiais. O acesso à justiça está atrelado aos conceitos de eficiência e celeridade, e os sistemas devem ser aprimorados para reduzir a duração do longo caminho que os cidadãos encontram para recuperar seus direitos (FERREIRA, 2015) ou ver a justiça sendo feita. Contudo, não se deve descuidar da validade jurídica dos atos judiciais informatizados, como, por exemplo, a publicidade do ato, a presença de um servidor da justiça e advogado junto ao réu ou testemunha na sala de audiências (com prévia comunicação aos defensores), entre outros.

Assim, após o aprofundamento da legislação pertinente ao assunto, constata-se que não há incompatibilidade entre o ordenamento jurídico brasileiro e a realização das Teleconferências, bem como verifica-se vantagens associadas a sua utilização (mais segurança aos envolvidos, celeridade na condução dos processos e economia de tempo e recursos públicos).

Entre as limitações do presente estudo, citam-se a reduzida amplitude da investigação realizada, haja vista a metodologia escolhida, assim como a ausência de verificação/análise in loco da utilização de Teleconferência em ambientes penais - o que poderia corroborar os resultados encontrados na revisão bibliográfica.

Ademais, a utilização de Teleconferências é um tema recente no âmbito jurídico, o que exige mais estudos e entendimento das partes envolvidas, sendo este artigo uma contribuição nesse sentido. Como sugestão para pesquisas futuras, entende-se importante o aprofundamento da opinião dos envolvidos (juízes, promotores, réus, advogados, entre outros), a respeito dos benefícios e das objeções de sua utilização. Além disso, estudos que analisem as atuais condições da estrutura carcerária para possível implantação de salas de Teleconferência seria de grande valia. É preciso, portanto, que haja um contínuo aprimoramento desse novo sistema de trabalho, atentando-se para o cumprimento das prerrogativas constantes na Constituição da República Federativa do Brasil.

\section{REFERÊNCIAS}

ANDRADE, Maria M. de. Introdução à metodologia do trabalho científico. 10. ed. São Paulo: Atlas, 2010.

BARROS, Marco Antonio de. Teleaudiência criminal: primeiros registros de sua realização no judiciário paulista. Revista CEJ, Brasília, v. 48, n. 48, p. 52-59, jan./mar. 2010.

BARROS, Marco Antonio de; ROMÃO, César Eduardo Lavoura Internet e videoconferência no processo penal. Revista CEJ, Brasília, v. 10, n. 32, p. 116-125, jan./mar. 2006.

BEAN, John P. Intellect, light, and shadow in research design. In: CONRAD, Clifton F.; SERLIN, Ronald (org.). The SAGE Handebook for research in education: pursuing ideas as the keystone of exemplar inquiry. California: SAGE Publications, Inc., 2011. p. 165-182.

BELLONE, Eric T. Private attorney-client communications and the effect of videoconferencing in the courtroom. Journal of International Commercial Law and Technology, v. 8, n. 1, p. 24-48, 2013.

BRASIL. Decreto-Lei n 3.689, de 03 de outubro de 1941. Código de Processo Penal. 1941. Disponível em: http://www.planalto.gov.br/ccivil_03/Decreto-Lei/Del3689.htm. Acesso em: 04 jan. 2019.

BRASIL. Constituição da República Federativa do Brasil de 1988. 1998. Disponível em: http://www.planalto.gov.br/ccivil_03/constituicao/constituicao.htm. Acesso em: 21 jan. 2020. 
BRASIL. Decreto No 592, de 6 de julho de 1992. Atos Internacionais. Pacto Internacional sobre Direitos Civis e Políticos. Promulgação. 1992. Disponível em: http://www.planalto.gov.br/ccivil_03/decreto/19901994/d0592.htm. Acesso em: 21 jan. 2020.

BRASIL. Lei n 9.099, de 26 de setembro de 1995. Dispõe sobre os Juizados Especiais Cíveis e Criminais e dá outras providências. 1995. Disponível em: http://www.planalto.gov.br/ccivil_03/leis/L9099.htm. Acesso em: 15 jan. 2019.

BRASIL. Lei no 10.259, de 12 de julho de 2001. Dispõe sobre a instituição dos Juizados Especiais Cíveis e Criminais no âmbito da Justiça Federal. 2001. Disponível em: http://www.planalto.gov.br/ccivil_03/leis/LEIS_2001/L10259.htm. Acesso em: 10 jan. 2019.

BRASIL. Decreto No 5.015, de 12 de março de 2004. Promulga a Convenção das Nações Unidas contra o Crime Organizado Transnacional. 2004. Disponível em: http://www.planalto.gov.br/ccivil_03/_ato20042006/2004/decreto/d5015.htm. Acesso em: 21 jan. 2020.

BRASIL. Lei n 11.419, de 19 de dezembro de 2006. Dispõe sobre a informatização do processo judicial; altera a Lei no 5.869, de 11 de janeiro de 1973 - Código de Processo Civil; e dá outras providências. 2006. Disponível em: http://www.planalto.gov.br/ccivil_03/_Ato2004-2006/2006/Lei/L11419.htm. Acesso em 16 jan. 2019.

BRASIL. CONSELHO NACIONAL DE JUSTIÇA (CNJ). Resolução CNJ n. 105, de 06 de abril de 2010. Dispõe sobre a documentação dos depoimentos por meio do sistema audiovisual e realização de interrogatório e inquirição de testemunhas por videoconferência. 2010a. Disponível em: http://www.cnj.jus.br/atosnormativos?documento=166. Acesso em: 20 jan. 2019.

BRASIL. CONSELHO NACIONAL DE JUSTIÇA (CNJ). Resolução CNJ n. 125, de 29 de novembro de 2010. Dispõe sobre a Política Judiciária Nacional de tratamento adequado dos conflitos de interesses no âmbito do Poder Judiciário e dá outras providências. 2010b. Disponível em:

https://www.cnj.jus.br/images/atos_normativos/resolucao/resolucao_125_29112010_11032016162839.pdf. Acesso em: 15 jan. 2019;

BRASIL. CONSELHO NACIONAL DE JUSTIÇA (CNJ). Resolução CNJ n. 213, de 15 de dezembro de 2015. Dispõe sobre a apresentação de toda pessoa presa à autoridade judicial no prazo de 24 horas. 2015.

Disponível em:

https://www.cnj.jus.br/images/atos_normativos/resolucao/resolucao_213_15122015_23112018141721.pdf. Acesso em: 13 jan. 2019.

BRASIL. CONSELHO NACIONAL DE JUSTIÇA (CNJ). Justiça em Números 2018: ano-base 2017/Conselho Nacional de Justiça - Brasília: CNJ, 2018a. Disponível em: https://www.cnj.jus.br/files/conteudo/arquivo/2018/08/44b7368ec6f888b383f6c3de40c32167.pdf. Acesso em: 20 jan. 2019.

BRASIL. CONSELHO NACIONAL DE JUSTIÇA (CNJ). Sistema Nacional de Videoconferência. 2019. Disponível em: http://cnj.jus.br/sistemas/sistema-nacional-de-videoconferencia. Acesso em: 22 fev. 2019.

BRASIL, Lei no 13.603, de 9 de janeiro de 2018. Altera a Lei no 9.099, de 26 de setembro de 1995, para incluir a simplicidade como critério orientador do processo perante os Juizados Especiais Criminais. 2018b. Disponível em: http://www.planalto.gov.br/ccivil_03/_Ato2015-2018/2018/Lei/L13603.htm. Acesso em: 15 jan. 2019.

CAMARGO, Jayme Silvestre Corrêa. Audiência de custódia - vantagens e desvantagens. Amagis Jurídica, n. 12, jan/jun. 2015. 
Disponível em: https://www.cidh.oas.org/basicos/portugues/c.convencao_americana.htm. Acesso em: 21 jan. 2010.

COOPER, Donald R.; SCHINDLER, Pamela S. Métodos de pesquisa em administração. 7. Ed. Porto Alegre: Bookman, 2003.

CORDEIRO, Néfi; COUTINHO, Nilton Carlos de Almeida. A audiência de custódia e seu papel como instrumento constitucional de concretização de direitos. Revista de Estudos Constitucionais,

Hermenêutica e Teoria do Direito (RECHTD), v. 10, n. 1. Jan/abr. 2018. DOI 10.4013/rechtd.2018.101.06.

Disponível em: http://revistas.unisinos.br/index.php/RECHTD/article/view/rechtd.2018.101.06. Acesso em: 15 dez. 2019.

CROTTY, Michael. The foundations of social research: meaning and perspective in the research process. California: SAGE Publications Ltd, 1998.

D'URSO, Luíz Flávio Borges. O interrogatório por teleconferência: uma desagradável justiça virtual. Revista Jus Navigandi, ano 7, n. 60, 01 nov. 2002. Disponível em: https://jus.com.br/artigos/3471/o-interrogatoriopor-teleconferencia. Acesso em: 14 out. 2018.

FERREIRA, Katia Balbino de Carvalho. Cyberjustice in Brazil - the use of technology to enhance access to justice and procedural celerity. 2015. 148 f. Tese (Doutorado em Direito) - Université de Montréal, 2015.

FIOREZE, Juliana. O interrogatório on-line como fator revolucionário na aplicação da justiça: aspectos críticos. Rev. de Ciên. Jur. e Soc. da Unipar, v. 8, n. 2, p. 187-205, jul./dez., 2005.

FREIRE, Débora Ribeiro Sá. Percepções da audiência virtual no Vale do Paraíba Fluminense. AREL FAAR, Ariquemes, RO, v. 1. n. 1, p. 96-107, maio 2013. DOI 10.14690/2317-8442.2013v11102. Disponível em: http://www.faar.edu.br/portal/revistas/ojs/index.php/arel-faar/article/view/102. Acesso em: 01 dez. 2018.

GOMES, Adalmir Oliveira; FREITAS, Maria Eduarda Mendonça de. Correlação entre demanda, quantidade de juízes e desempenho judicial em varas da Justiça Federal no Brasil. Revista Direito GV, São Paulo, v. 13, n. 2, p. 567-585, 2017. DOI 10.1590/2317-6172201722. Disponível em:

http://www.scielo.br/scielo.php?script=sci_arttext\&pid=S1808-24322017000200567\&lng=pt\&tlng=pt. Acesso em: 15 mar. 2019.

GOMES, Rodrigo Carneiro. A videoconferência ou interrogatório on-line, seus contornos legais e a renovação do processo penal célere e eficaz. Jurisp. Mineira, Belo Horizonte, v. 58, n. 182, p. 19-30, jul./set. 2007.

GOMES, Rodrigo Carneiro. A videoconferência ou interrogatório on-line. Revista CEJ, Brasília, Ano XII, n. 40, p. 68-72, jan./mar. 2008.

GOMES, Rodrigo Carneiro. A Lei n. 11.900/2009 e a adoção da videoconferência no Brasil. Revista CEJ, Brasília, v. 13, n. 47, p. 84-93, out./dez. 2009.

GUIMARÃES, Tarsila. Interrogatório por videoconferência e os direitos fundamentais. Revista Direitos Fundamentais \& Democracia, v. 4, n. 4, jul./dez. 2008.

HAIR JR, Joe F. et al. Essentials of business research methods. 2. ed. New York: M.E. Sharpe, 2011.

JOHNSON, Molly Treadway; WIGGING, Elizabeth C. Videoconferencing in criminal proceedings: legal and empirical issues and directions for research. Law \& Policy, v. 28, n. 2, p. 211-227, 2006. DOI 10.1111/j.14679930.2006.00224.x. Disponível em: https://onlinelibrary.wiley.com/doi/full/10.1111/j.1467-

9930.2006.00224.x. Acesso em: 22 jan. 2019.

LIMA, Telma Cristiane Sasso de; MIOTO, Regina Célia Tamaso. Procedimentos metodológicos na construção do conhecimento científico: a pesquisa bibliográfica. Revista Katálysiss, v. 10, n. esp. p. 37-45, 2007. DOI 
10.1590/S1414-49802007000300004. Disponível em:

http://www.scielo.br/scielo.php?script=sci_arttext\&pid=S1414-49802007000300004. Acesso em: 08 jan. 2019.

McKAY, Carolyn. Video links from prision: permeability and the carceral world. International Journal of Crime, Justice and Social Democracy, v. 5, n. 1, p. 21-37, 2016. DOI 10.5204/ijcjsd.v5i1.283. Disponível em: https://papers.ssrn.com/sol3/papers.cfm?abstract_id=2937479. Acesso em: 22 fev. 2019.

ORMSTON, Rachel et al. The foundations of qualitative research. In: RITCHIE, Jane et al. (org.). Qualitative research practice: a guide for social science students \& researchers. 2. ed. Los Angeles: SAGE Publications Ltd, 2014. p. 2-26.

PIZZANI, Luciana et al. A arte da pesquisa bibliográfica na busca do conhecimento. Revista Digital de Biblioteconomia e Ciência da Informação, v. 10, n. 1, p. 53-66, jul./dez. 2012. DOI 10.20396/rdbci.v10i1.1896. Disponível em: https://periodicos.sbu.unicamp.br/ojs/index.php/rdbci/article/view/1896. Acesso em: 22 dez. 2018.

PRADO, Wagner Junqueira. A videoconferência como política pública. Revista Brasileira de Políticas Públicas, Brasília, v. 1, n. 2, p. 75-110, jul./dez. 2011. DOI 10.5102/rbpp.v1i2.1255. Disponível em: https://www.publicacoesacademicas.uniceub.br/RBPP/article/view/1255. Acesso em: 18 dez. 2018.

PRADO, Wagner Junqueira. Videoconferência no processo penal: aspectos jurídicos, políticos e econômicos. Brasília: TJDFT, 2015.

RAY, Ajoy; ACHARYA, Tinku. Information Technology: principles and applications. New Delhi: Prentice-Hall, 2004.

REYNOLDS, George W. Information Technology for managers. 2ed. Boston: CENGAGE Learning, 2016.

RIBEIRO, Renata Isabela; NOVAES, Pedro Luís Piedade. A audiência de custódia no sistema processual penal brasileiro. Revista Juris UniToledo, v. 3, n. 1, p. 223-242, jan./mar. 2018.

ROWDEN, Emma; WALLACE, Anne. Remote judging: the impact of video links on the image and the role of the judge. International Journal of Law in Context, v. 14, n. 14, p. 504-524, 2018. DOI 10.1017/S1744552318000216. Disponível em: https://www.cambridge.org/core/journals/internationaljournal-of-law-in-context/article/remote-judging-the-impact-of-video-links-on-the-image-and-the-role-ofthe-judge/D395FCC43E27CE86C248538382C8DFEC\#. Acesso em: 20 jan. 2019.

SALES; Lilia Maia de Morais; CHAVES, Emmanuela Carvalho Cipriano. Mediação e conciliação judicial - a importância da capacitação e de seus desafios. Sequência (Florianópolis), v. 35, n. 69, p. 255-280, 2014. DOI 10.5007/2177-7055.2014v35n69p255. Disponível em:

https://periodicos.ufsc.br/index.php/sequencia/article/view/2177-7055.2014v35n69p255. Acesso em: 24 fev. 2019.

SANTOS, Julia Ângela Timóteo dos. Audiência de custódia: considerações e possibilidades. Revista da ESMAL, n. 1, p. 322-339, 2016.

SOARES, Júlio Cesar Simbra; MACHADO, Eduardo Marques. Videoconferências como meio de produção de atos processuais: Limites e perspectivas. Revista Jurídica da Faminas, v. 2, p. 111-127, 2007.

SOARES, Sando Vieira; PICOLLI, Icaro Roberto Azevedo; CASAGRANDE, Jacir Leonir. Pesquisa bibliográfica, pesquisa bibliométrica, artigo de revisão e ensaio teórico em Administração e Contabilidade.

Administração: Ensino e Pesquisa, Rio de Janeiro, v. 19, n. 2, p. 308-339, mai./ago. 2018. DOI 10.13058/raep.2018.v19n2.970. Disponível em: https://raep.emnuvens.com.br/raep/article/view/970. Acesso em: 15 jan. 2019. 
SOUZA, Josie Adriane Marques Alves de; NUNES, Geilson. Uma análise da audiência de custódia: seus fundamentos e finalidades. Direito \& Realidade, v. 6, n. 6, p. 96-129, 2018.

TAVARES, Magno Silva. Aspectos Doutrinários da Nova Lei de Videoconferência: Lei 11.900/2009. Caderno Virtual, v. 1, n. 1, p. 1-15, 2011.

TOZONI-REIS, Marília F. de C. Metodologia da pesquisa. 2. ed. Curitiba: IESDE Brasil, 2009.

YAMAGATA, Hisashi; FOX, Danielle. Evaluating the use of videoconferencing technology in domestic violence ex parte hearings: assessing procedural consistency. Justice System Journal, v. 38, n. 2, p. 135-148, 2017. DOI 10.1080/0098261X.2016.1251363. Disponível em: https://www.tandfonline.com/doi/full/10.1080/0098261X.2016.1251363. Acesso em: 21 fev. 2019. 